\title{
Evaluation of Medical Emergency Team Activation in Surgical Wards
}

\author{
Moon Suk Choi a, Dae Sang Lee b, Chi Min Park c,* \\ a Department of General Surgery, Sungkyunkwan University, College of Medicine, Samsung Medical Center, Seoul, Korea \\ ${ }^{b}$ Department of Trauma Surgery, College of Medicine, The Catholic University of Korea, Seoul, Korea \\ ${ }^{c}$ Department of Critical Care Medicine, Samsung Medical Center, Sungkyunkwan University School of Medicine, Seoul, Korea
}

Article history:

Received: October 10, 2018

Revised: October 17, 2018

Accepted: October 18, 2018

\section{ABSTRACT}

Purpose: A review was performed to determine the frequency of activating medical emergency teams (MET) in surgical wards, so that resource allocation could be optimized.

Methods: A retrospective observational study was performed to determine the time and frequency when MET were deployed $(N=465)$ to patients $(n=387)$ who were admitted to the surgical ward, from March 2013 to July 2016 due to emergency situations.

Results: Of the 465 MET activations, 8 did not incur any further intervention. The review showed an average of 151 minutes from onset of symptoms to MET activation, and an average of 110 minutes until intervention (additional diagnosis / treatment). The number of MET activations increased year by year from 2013 to 2016. The transfer of patients to the intensive care units also increased from 34 in 2013, to 82 in 2016. The lowest number of MET activations occurred between 04:00 and 05:00, but there was no difference in the number of MET activations between day and night. However, MET activation in response to acute respiratory distress was significantly higher during the nighttime $(p=0.003)$.

Conclusion: Patients admitted to a surgical ward have more serious complications. This study showed that the use of MET in surgical wards has increased year by year, and the frequency of calls between day and night was not different, except higher MET activations observed at night in patients with acute respiratory distress.

Keywords: hospital rapid response team, general surgery, intensive care unit, hospital mortality, rapid response systems

\section{Introduction}

The rapid response system (RRS) which may include a medical emergency team (MET), has been introduced into hospitals to decrease morbidity and mortality through the early detection of patients at risk of further deterioration [1,2]. These RRS provide additional information and assistance to the ward and intensive care unit, thus aiding diagnosis and treatment decisions for the patient. Following the introduction of the RRS, patient mortality rates have significantly decreased [3]. The need for RRS's within hospitals is clear. This system improves the safety of patients in hospital, whose condition has deteriorated [4]. If an emergency occurs, patients are treated by the MET. In surgical wards, there are not always enough medical staff present on the ward. Surgical residents take part in the operation room after medical rounds and often only 1 doctor may be present on the ward. In addition, in the absence of senior staff, such as in the event of an emergency resulting from peri-operative complications, a junior resident may determine the diagnosis and treatment direction.

In this study, the reasons for activating the RRS were analyzed in relation to the patients' medical conditions whilst on the surgical ward), and the time at which the RRS was initiated was recorded. In particular, we investigated whether 
there was a difference in the time of event occurrence in the surgical general ward depending on the number of medical staff, and the time required for patient intervention. Diurnal variation was investigated (by classifying daytime and nighttime) related to an increase / decrease of medical staff present on the surgical ward. The results of this study may be used to determine the distribution of medical resources within a hospital.

\section{Materials and Methods}

A retrospective observational study was performed to evaluate the effect of the MET of a RRS in general surgery wards. The study included patients admitted to the surgical wards of a 1,960-bed, university affiliated, tertiary referral hospital in Seoul, South Korea from May 2013 to July 2016. The surgical ward [ 8 wards of general surgery (50-60 beds per ward)] provided general care for approximately 320 to 400 patients per day. The Institutional Review Board approved the review and presentation of the information obtained from the patient records.

\section{Study population}

A MET is a specialist team that identifies and treats patients whose clinical symptoms have deteriorated (soon after surgery). To address whether the time of initiation of a MET response was associated with improved mortality rates among patients in the surgical wards, the clinical data of patients whose symptoms activated the MET were analyzed. Those patients who required surgery or underwent surgery were reviewed. Among these patients, those who had an emergency or needed to be transferred to the intensive care unit (ICU) were included in this study. There were a total of 465 MET activations evaluated which were initiated from 387 patients. Conditions concerning the airways, circulation, neurology, and bedside concerns were categorized as a MET activation. The time of a MET activation was also recorded to check whether there was diurnal variation in MET activations. In addition, the classification of daytime hours (08:00-17:59) and nighttime hours (18:00-07:59) enabled checks of the MET call out rate according to the medical staff shifts (MET activation was limited to doctors and nurses on the ward). In addition, the ICU physician was aware of the patient's condition through electronic medical records in the hospital.

\section{RRS}

A rapid response system with a MET was implemented in March 2009 [4-6]. The team consisted of academic fellows that were training in critical care, or senior residents in internal medicine. The criteria for the activation of a MET were prominently displayed on computer monitors in each ward. When the primary care physician and the nurse perceived a patient to be experiencing a worsening condition (that satisfied

Table 1. Activation criteria for MET between 2013 and 2016.

\begin{tabular}{|c|c|c|c|c|}
\hline \multicolumn{5}{|c|}{ Pts (\%) } \\
\hline & 2013 & 2014 & 2015 & 2016 \\
\hline Criteria for initiating a MET & 67 & 113 & 142 & 143 \\
\hline $\begin{array}{l}\text { Acute respiratory distress } \mathrm{RR}>30 \text { or }<8 \\
\text { breaths/min }\end{array}$ & $10(14.9)$ & $20(17.7)$ & $29(20.4)$ & $34(23.8)$ \\
\hline $\begin{array}{l}\text { Acute hypoxia oxygen saturation derived } \\
\text { from pulse oximetry }<85 \%\end{array}$ & $16(23.9)$ & $26(23.0)$ & $25(17.6)$ & $37(25.9)$ \\
\hline $\mathrm{PaCO} 2>50 \mathrm{mmHg}$ & 0 & $3(2.7)$ & $2(1.4)$ & $1(0.7)$ \\
\hline Upper airway obs. & 0 & $3(2.7)$ & $4(2.8)$ & $1(0.7)$ \\
\hline $\mathrm{SBP}<85 \mathrm{mmHg}$ & $23(34)$ & $29(25.6)$ & $41(28.8)$ & $39(27.2)$ \\
\hline Acute chest pain & 0 & $5(4.4)$ & $5(3.5)$ & 0 \\
\hline $\mathrm{HR}>130 \mathrm{bpm}$ & $20(29.8)$ & $44(38.9)$ & $53(37.3)$ & $47(32.8)$ \\
\hline Arrhythmia with Sx & $1(1.4)$ & $5(4.4)$ & $5(3.5)$ & $5(3.4)$ \\
\hline Sudden change in mental state & $5(7.4)$ & $17(15)$ & $8(5.6)$ & $14(9.7)$ \\
\hline Seizure & 0 & $2(1.7)$ & $2(1.4)$ & $1(0.7)$ \\
\hline Bedside concern & $7(10.4)$ & $10(8.8)$ & $18(12.6)$ & $23(16.0)$ \\
\hline
\end{tabular}

$\mathrm{MET}=$ medical emergency team; Obs = obstructions; $\mathrm{paCO} 2$ = partial pressure of carbon dioxide; $\mathrm{RR}=$ respiratory rate; $\mathrm{Sx}=$ symptoms. $\mathrm{SBP}=$ systolic blood pressure, $\mathrm{HR}=$ heart rate. 
activation criteria), the MET were activated (Table 1 ). The patient would arrive within 10 minutes and would be assessed by the MET within 30 minutes. Thereafter, the patient would be diagnosed and the appropriate treatment administered. After which an additional plan would be made (according to the symptoms of each patient), and an ICU transfer or a "do not resuscitate" would be considered [7].

\section{Criteria for MET activation}

The criteria for a MET activation were based on acute respiratory distress ( $<8$ or $>30$ breaths/minutes), acute hypoxia [oxygen saturation derived from pulse oximetry (85\%)], high $\mathrm{PaCO} 2>50 \mathrm{mmHg}$, upper airway obstruction, low systolic blood pressure $<85 \mathrm{mmHg}$, acute chest pain, elevated heart rate $>130 \mathrm{bpm}$, arrhythmia (electrocardiogram proven) with symptoms, sudden change in mental state, and experiencing a seizure. In addition, to these criteria, medical staff (physicians and nurses) noted patients' bedside concerns/wellbeing.

\section{Data collection}

The data were collected retrospectively (May 2013-July 2016). A set of activation criteria based on abnormal physiological variables was used by physicians and nurses to activate the MET (Table 1), with a single criterion sufficient to warrant the activation of a MET. Details of all MET call outs were noted as soon as possible after the event by a duty member, and entered into a registry with patient demographics, times of MET activations and deactivation, intervention period, reasons for MET activation, clinical findings on arrival, interventions delivered, and final outcomes of the clinical episode [8-10].

\section{Statistical analysis}

In this study, all data are presented as the median range or as the number of patients. Activation of the MET was measured as the time of the first call. Activation time was measured from the moment the MET physically examined the patient to the time the intervention was started or second decision was made. To investigate the daytime and nighttime activation rates of the MET in the surgical wards, the activation time of MET during the periods 08:00 until 17:59, and 18:00 until 07:59 were compared. Data were analyzed using IBM SPSS statistics 20 (IBM, Armonk, NY). All data were measured with decriptive analysis. Comparisons of data for differences in proportions between day and night periods were performed using $\chi^{2}$ or Fisher's excat test. For all statistical analysis, $p<0.05$ was considered statistically significant.

\section{Results}

The number of times MET activation occurred in the surgical wards were recorded from 2013 to 2016. All patients fulfilled the criteria required for the MET activation, and had undergone surgery or needed surgery. Data was obtained from 465 MET events. The mean patient age was 65.5 years and $68 \%$ of patients were male. There were 67 MET activations in 2013, 143 in 2014, 142 in 2015, and 143 in 7 months in 2016. Among 465 total MET activations, there were 8 cases in which no additional intervention was performed. Reasons for no additional medical intervention included patient or care-giver's refusal, wrong contact, or direct intervention in the hospital.

The average time from the moment the symptoms first appeared until the MET activation was 151 minutes. It took an average of 110 minutes to determine the additional medical intervention required, "do not resuscitate," or ICU transfer. The number of ICU transfers increased annually from 34 patients in 2013, to 82 patients in 2016 (Table 2). MET activation increased markedly during the surgeons routine ward round between 08:00 and 10:00, with a peak call out of 25 MET activations, after which this decreased to 17 call outs at 12:00, and peaked at its highest between 17:00 to 18:00 (31 call outs) with the

Table 2. Annual distribution figures for activation of the MET according to daytime or nighttime initiation.

\begin{tabular}{|c|c|c|c|c|c|}
\hline \multicolumn{6}{|c|}{ Year } \\
\hline & Total & 2013 & 2014 & 2015 & 2016 \\
\hline MET call & 465 & 67 & 113 & 142 & 143 \\
\hline Age mean & 65.5 & 64 & 66 & 66 & 66 \\
\hline Gender (\%, male) & 317 & $42(62)$ & $82(72)$ & $88(61)$ & $105(73)$ \\
\hline Calling time for MET (min) & & 169 & 92 & 164 & 182 \\
\hline \multirow[t]{2}{*}{ MET activation time (median min) } & & 42 & 58 & 70 & 86 \\
\hline & & $34(50.7)$ & $63(55.7)$ & $74(52.1)$ & $82(57.3)$ \\
\hline
\end{tabular}

ICU = intensive care units; MET = medical emergency team. 


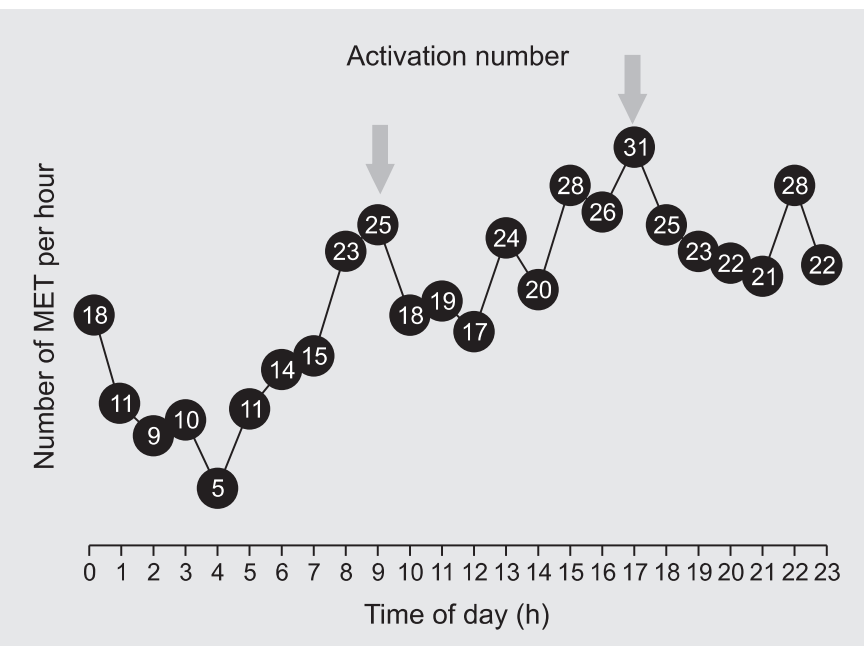

Figure 1. The number of MET responses made per hour over a 24hour period. An illustration of the numbers and times at which METs responded. The data is representative of 465 activations made between 2013-2016. The arrows demonstrate when the doctors made their medical rounds.

MET = medical emergency team.

Table 3. MET activations during the day and night.

\begin{tabular}{|cccc}
\hline \multicolumn{4}{c}{ Number of activations, $n(\%)$} \\
\hline Time characteristics(y) & Day time & Night time & $p$ \\
\hline 2013 & $31(46.3)$ & $36(53.7)$ & \\
2014 & $55(48.7)$ & $58(51.3)$ & \\
2015 & $75(52.8)$ & $67(47.2)$ & \\
2016 & $70(49.0)$ & $73(51.0)$ & 0.815 \\
\hline
\end{tabular}

MET = medical emergency team .

second ward round of the day (Figure 1 ). The time with the least number of call outs ( 5 call outs) was between 04:00 and 05:00 (Figure 1). The number of MET activations increased annually. There was no significant difference in the number of MET activations between daytime and night-time (Table 3).

\section{Comparison of MET activations between daytime and nighttime}

Of the total 465 MET activations between 2013 to 2016, 231 (48\%) were during the daytime and 234 (52\%) were during nighttime, showing no difference in MET activations between day and night. Patient characteristics and the reasons for MET activation were similar between day and night. However, the number of patients with acute respiratory distress requiring MET intervention were higher during the nighttime (16.0\% versus $23.9 \%, p=0.003$; Table 4 ). All other criteria listed that could result in a MET response were not significantly different between daytime and nighttime without acute respiratory distress.
Table 4. Criteria for a MET response during the day and night.

\begin{tabular}{|c|c|c|c|}
\hline Criteria for a MET call out & Day/night & No. of Pts (\%) & $P$ \\
\hline \multirow{2}{*}{$\begin{array}{l}\text { Acute respiratory distress } \\
\mathrm{RR}>30 \text { or }<8 \text { breaths/min }\end{array}$} & Day & $37(16)$ & \multirow[t]{2}{*}{0.032} \\
\hline & Night & $56(23.9)$ & \\
\hline \multirow{2}{*}{$\begin{array}{l}\text { Acute hypoxia oxygen } \\
\text { saturation derived from } \\
\text { pulse oximetry }<85 \%\end{array}$} & Day & $56(24)$ & \multirow[t]{2}{*}{0.335} \\
\hline & Night & $48(20.5)$ & \\
\hline \multirow{2}{*}{$\mathrm{PaCO}_{2}>50 \mathrm{mmHg}$} & Day & $1(0.5)$ & \multirow[t]{2}{*}{0.216} \\
\hline & Night & $5(2.1)$ & \\
\hline \multirow{2}{*}{ Upper airway obstruction } & Day & $6(2.5)$ & \multirow[t]{2}{*}{0.174} \\
\hline & Night & $2(0.8)$ & \\
\hline \multirow{2}{*}{$\mathrm{SBP}<85$} & Day & $65(28)$ & \multirow[t]{2}{*}{0.906} \\
\hline & Night & $67(28.6)$ & \\
\hline \multirow{2}{*}{ Acute chest pain } & Day & $5(2.1)$ & \multirow[t]{2}{*}{0.616} \\
\hline & Night & $5(2.1)$ & \\
\hline \multirow{2}{*}{$\mathrm{HR}>130$} & Day & $81(35.0)$ & \multirow[t]{2}{*}{0.927} \\
\hline & Night & $83(35.4)$ & \\
\hline \multirow{2}{*}{ Arrhythmia with sx } & Day & $11(4.7)$ & \multirow[t]{2}{*}{0.120} \\
\hline & Night & $5(2.1)$ & \\
\hline \multirow{2}{*}{$\begin{array}{l}\text { Sudden change } \\
\text { in mental state }\end{array}$} & Day & $23(10)$ & \multirow[t]{2}{*}{0.717} \\
\hline & Night & $21(8.9)$ & \\
\hline \multirow{2}{*}{ Seizure } & Day & $2(0.8)$ & \multirow[t]{2}{*}{$0.50 €$} \\
\hline & Night & $3(1.2)$ & \\
\hline \multirow{2}{*}{ Bedside concern } & Day & $30(13)$ & \multirow[t]{2}{*}{0.739} \\
\hline & Night & $28(12)$ & \\
\hline \multirow{2}{*}{ Transfer to ICU } & Day & $128(55)$ & \multirow[t]{2}{*}{0.666} \\
\hline & Night & 125 (53) & \\
\hline
\end{tabular}

$\mathrm{HR}=$ heart rate; $\mathrm{ICU}=$ Intensive care units; $\mathrm{MET}$ = medical emergency team; $\mathrm{paCO}_{2}=$ partial pressure of carbon dioxide; $\mathrm{RR}=$ respiratory rate; $\mathrm{SBP}=$ systolic blood pressure; $\mathrm{sX}=$ symptoms.

\section{Discussion}

In medical wards, patients may be old or have co-morbidities but there are enough physicians to cover ward rounds, care stations and wards, and for this reason the probability of a MET activation is low. However, in surgical wards, most patients do not have an underlying disease and are not typically old. Patients undergoing surgery are more likely suffer from perioperative complications in addition to common medical problems associated with their condition [11]. In addition, surgical residents also take part in the operation room after medical rounds. There are often no doctors or only 1 
doctor on the ward. Due to the absence of a professor or senior residents in the event of an emergency (such as perioperative complication of the patient), a junior resident may be responsible for determining the diagnosis and treatment direction. Due to their lack of experience, a patient's treatment can be delayed and compromised. In an attempt to address these issues, the development of RRS in hospitals may help to improve patient care. The activation of MET as part of the RRS is known to help reduce mortality. Kwak et al [12] reported that hospital code rates decreased by $31.1 \%$, and the mean inhospital mortality rate was reduced by $15.3 \%$ following the launch of RRS. Jones et al [13] also reported that MET activation increased long term survival of patients. Tobins et al [14] have shown that MET activation can reduce major metropolitan health network mobility. Tobins et al [14] have shown that Presence of a hospital MET system can reduce hospital mortaliy across a major metropolitan health network. However it appered to take more than 2 years after the implement.

Among the 465 MET activations, the most frequent activation period was from 17:00 to 18:00, with 31 activations, and the least number of activations in the period from 03:00 to 04:00. In order to identify vulnerable time periods on the surgical ward, the regular working hours of the residents at 08:00 to 17:59 (daytime) and 18:00 to $07: 59$ (nighttime) were examined. There were no significant differences in MET activation between day and night. However, MET activation increased when residents were on the ward round.

There were $50 \%$ of patients treated by a MET who were transferred to ICU, indicating the severity of conditions met by the METs. In this study, the average time from symptom onset to MET activation ranged from 86 to 143 minutes due to "trial-and-error delays" after the introduction of the RRS, where junior residents activated the MET. As a patient's condition deteriorates, the probability of needing care on an ICU increases [15]. In order to prevent "trial-and-error delays" the RRS needs to be automated with an urgent message system to team members of the EMT.

To understand the changes in a patient's condition and reasons for a medic's request for a MET activation to carry out additional assessment and treatment is important. In this study, the MET call outs increased between 08:00 to 10:00, after the end of ward rounds, and then decreased after the surgeon moved to the operating theater. In the afternoon, when patients returned to the wards after their operations, MET call outs increased. The highest rate was observed around 18:00 when the afternoon ward round had finished. This indicated that there was an identifiable need for staff to remain on the ward when patients returned after their operation to quickly identify and respond to changes in a patient's condition.

The number of MET activations did not differ significantly between daytime and nighttime. During the daytime, post operation complications occurred after elective operations and this increased the number of activations of the MET. At nighttime, acutely deteriorating patients had a higher risk of in-hospital mortality [16]. Daytime emergencies can be resolved through consultation with other departments, even if the patient's condition has met the MET activation criteria. However, at nighttime, the duty resident may manage the ward by themselves, and consultation with other departments is limited. Despite this, the activation of the MET did not show any differences between daytime and nighttime, however mortality and morbidity were not studied.

Medical staff should be able to stay in the ward as much as possible and the amount of time medical staff have been absent from the ward is decreasing. Recently, a system in the ward has been newly established with the introduction of a medic who can perform the role of the resident on the ward. In addition, in-patient satisfaction increased when a hospitalbased general physician took charge of the work [9]. Although the system has not yet fully established and the physicians proficiency has not been developed [15], it can be expected their presence on the ward and care of patients will reduce the amount of time before activation of the MET. They can also help prepare for preliminary evaluations before further intervention directed by the MET.

This study has some limitations including non-classification of weekends and weekdays in this study. There may be differences in regular working hours without surgery between weekdays and weekends. During the 7 days of a week, 5 days are regular working days. However, on Saturdays and Sundays, doctors do not perform elective surgery so there is no decrease in the number of medical staff on the wards due to surgery on weekends but, the number of staff in attendance is lower. MET activation may occur more frequently towards the end of the week and on weekends. In addition, in-hospital mortality was not investigated in this study because the research objective was to determine whether activation of METs increased at vulnerable times of the day. The results of this study showed that MET activation increased during daytime when medical staff were absent. The RRS system and use of METs reduces mortality and morbidity $[3,13,14]$. However, recently it has been suggested that activation of METs is not associated with inhospital mortality $[17,18]$. Further studies are needed regarding in-hospital mortality on surgical wards, patient safety and the effects of METs.

In conclusion, the rate of MET activation in hospitals is increasing every year. Whether the RRS and specifically METs can reduce mortality is controversial and requires further study. The results in this study suggest that it may be beneficial to routinely introduce a physician to work on the surgical ward to improve patient safety. 


\section{Conflicts of Interest}

\section{Authors have no conflicts of interest to declare.}

\section{References}

[1] Herod R, Frost SA, Parr M, Hillman K, Aneman A. Long term trends in medical emergency team activations and outcomes. Resuscitation 2014;85(8):1083-7.

[2] Hillman K, Chen J, Cretikos M, Bellomo R, Brown D, Doig G, et al. Introduction of the medical emergency team (MET) system: A clusterrandomised controlled trial. Lancet 2005;365(9477):2091-7.

[3] Jung B, Daurat A, De Jong A, Ghanques G, Mahul M, Monnin M, et al. Rapid response team and hospital mortality in hospitalized patients. Intensive Care Med 2016;42(4):494-504.

[4] Jones DA, DeVita MA, Bellomo R. Rapid-response teams. N Engl J Med 2011;365(2):139-46.

[5] Song JU, Suh GY, Park HY, Lim SY, Han SG, Kang YR, et al. Early intervention on the outcomes in critically ill cancer patients admitted to intensive care units. Intensive Care Med 2012;38(9):1505-13.

[6] Lim SY, Park SY, Park HK, Kim M, Park HY, Lee B, et al., Early impact of medical emergency team implementation in a country with limited medical resources: a before-and-after study. J Crit Care 2011;26(4):373-8.

[7] Smith RL, Hayashi VN, Lee YI, Navarro-Mariazeta L, Felner K. The medical emergency team call: a sentinel event that triggers goals of care discussion. Crit Care Med 2014;42(2):322-7.

[8] Devita MA, Bellomo R, Hillman K, Kellum J, Rotondi A, Teres D. Findings of the first consensus conference on medical emergency teams. Crit Care Med 2006;34(9):2463-78.
[9] Chen LM, Birkmeyer JD, Saint S, Jha AK. Hospitalist staffing and patient satisfaction in the national Medicare population. J Hosp Med 2013;8(3):126-31.

[10] Lee DS, Suh GY, Ryu JA, Chung CR, Yang JH, Park CM, et al. Effect of Early Intervention on Long-Term Outcomes of Critically Ill Cancer Patients Admitted to ICUs. Crit Care Med 2015;43(7):1439-48.

[11] Cooper Z, Mitchell SL, Gorges RJ, Rosenthal RA, Lipsitz SR, Kelley AS. Predictors of Mortality Up to 1 Year After Emergency Major Abdominal Surgery in Older Adults. J Am Geriatr Soc 2015;63(12):2572-9.

[12] Kwak HJ, Yun I, Kim SH, Sohn JW, Shin DH, Yoon HJ, et al. The extended rapid response system: 1-year experience in a university hospital. J Korean Med Sci 2014;29(3):423-30.

[13] Jones D, Egi M, Bellomo R, Goldsmith D. Effect of the medical emergency team on long-term mortality following major surgery. Critical Care 2007;11(1):R12.

[14] Tobin AE, Santamaria JD. Medical emergency teams are associated with reduced mortality across a major metropolitan health network after two years service: a retrospective study using government administrative data. Crit Care 2012;16(5):R210.

[15] Goodwin JS, Salameh H, Zhou J, Singh S, Kuo YF, Nattinger AB. Association of Hospitalist Years of Experience With Mortality in the Hospitalized Medicare Population. JAMA Intern Med 2018;178(2):196-203.

[16] Fernando SM, Reardon PM, Bagshaw SM, Scales DC, Murphy K, Shen J, et al. Impact of nighttime Rapid Response Team activation on outcomes of hospitalized patients with acute deterioration. Crit Care 2018;22(1):67.

[17] Santamaria J, Moran J, Reid D. Increasing the Number of Medical Emergency Calls Does Not Improve Hospital Mortality. Crit Care Med 2018;46(7):1063-9.

[18] Massey D, Aitken LM, Chaboyer W. Literature review: do rapid response systems reduce the incidence of major adverse events in the deteriorating ward patient? J Clin Nurs 2010;19(23-24):3260-73. 